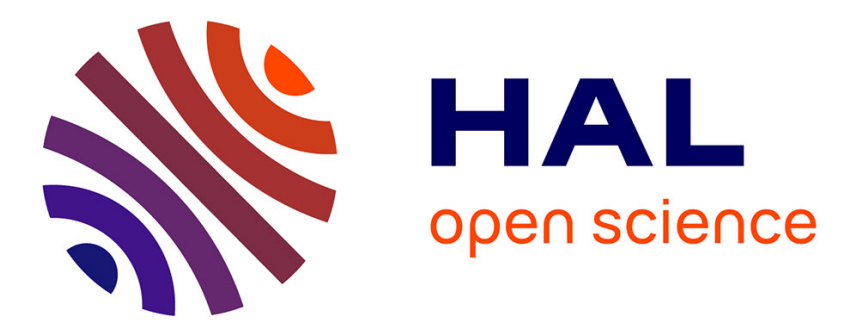

\title{
Quantified biotic and abiotic responses to multiple stress in freshwater, marine and ground waters
}

P. Nõges, C. Argillier, J.M. Garmendia, J. Hanganu, V. Kodes, F.

Pletterbauer, A. Sagouis, S. Birk

\section{- To cite this version:}

P. Nõges, C. Argillier, J.M. Garmendia, J. Hanganu, V. Kodes, et al.. Quantified biotic and abiotic responses to multiple stress in freshwater, marine and ground waters. Science of the Total Environment, 2016, 540, pp.43-52. 10.1016/j.scitotenv.2015.06.045 . hal-01237331

\section{HAL Id: hal-01237331 \\ https://hal.science/hal-01237331}

Submitted on 3 Dec 2015

HAL is a multi-disciplinary open access archive for the deposit and dissemination of scientific research documents, whether they are published or not. The documents may come from teaching and research institutions in France or abroad, or from public or private research centers.
L'archive ouverte pluridisciplinaire $\mathbf{H A L}$, est destinée au dépôt et à la diffusion de documents scientifiques de niveau recherche, publiés ou non, émanant des établissements d'enseignement et de recherche français ou étrangers, des laboratoires publics ou privés. 


\section{Quantified biotic and abiotic responses to multiple stress in freshwater, marine and ground waters}

Peeter Nõges $^{\mathrm{a}^{*}}$, Christine Argillier $^{\mathrm{b}}$, Ángel Borja ${ }^{\mathrm{c}}$, Joxe Mikel Garmendia ${ }^{\mathrm{c}}$, Jenică Hanganu ${ }^{\mathrm{d}}$, Vit Kodeš ${ }^{\mathrm{e}}$, Florian Pletterbauer ${ }^{\mathrm{f}}$, Alban Sagouis ${ }^{\mathrm{bg}}$, Sebastian Birk ${ }^{\mathrm{h}}$

${ }^{a}$ Estonian University of Life Sciences, Institute of Agricultural and Environmental Sciences, Centre for Limnology, 61117 Rannu, Tartu county, Estonia

${ }^{\mathrm{b}}$ Irstea, UR HYAX, Centre d'Aix-en-Provence, F-13612 Le Tholonet, France

${ }^{\mathrm{c}}$ AZTI, Marine Research Division, Herrera Kaia, Portualdea s/n, 20110 Pasaia, Spain

${ }^{d}$ Danube Delta National Institute for Research and Development 165 Babadag Street, Tulcea 820112, Romania

${ }^{\text {e }}$ Czech Hydrometeorological Institute, Department of Water Quality, Na Šabatce 17, 14306 Prague, Czech Republic

${ }^{\mathrm{f}}$ University of Natural Resources and Life Sciences, Institute of Hydrobiology and Aquatic Ecosystem Management, Max-Emanuel-Straße 17, 1180 Wien, Austria

${ }^{\mathrm{g}}$ Irstea, UR LISC, Centre de Clermont-Ferrand, F-63172 Aubière, France

${ }^{\mathrm{h}}$ Faculty of Biology, Department of Aquatic Ecology, University of Duisburg-Essen, Universitätsstraße 5, 45141 Essen, Germany

* Corresponding author. Tel.:+372 56078389 .

E-mail address: peeter.noges@emu.ee (P. Nõges). 


\begin{abstract}
We reviewed 219 papers and built an inventory of 532 items of ecological evidence on multiple stressor impacts in rivers, lakes, transitional and coastal waters, as well as groundwaters. Our review revealed that, despite the existence of a huge conceptual knowledge base in aquatic ecology, few studies actually provide quantitative evidence on multi-stress effects. Nutrient stress was involved in $71 \%$ to $98 \%$ of multi-stress situations in the three surface aquatic environments, and in $42 \%$ of those in groundwaters. However, their impact manifested differently along the groundwater-river-lake-transitional-coastal continuum, mainly determined by the different hydro-morphological features of these ecosystems. The reviewed papers addressed two-stressor combinations most frequently (42\%), corresponding with the actual status-quo of pressures acting on European surface waters as reported by the Member States in the WISE WFD Database (EEA 2015). Across all biological groups analysed, higher explanatory power of the stress-effect models was discernible for lakes under multi-stressor compared to single stressor conditions, but generally lower for coastal and transitional waters. Across all aquatic environments, the explanatory power of stress-effect models for fish increased when multi-stressor conditions were taken into account in the analysis, qualifying this organism group as a useful indicator of multi-stress effects. In contrast, the explanatory power of models using benthic flora decreased under conditions of multiple stress.
\end{abstract}

\title{
Keywords
}

Stressor combination, stressor interaction, biological group, nutrient stress, hydromorphology, paradigm 


\section{Introduction}

In our globalising world, multiple stresses on surface and groundwater systems from natural and man-made disturbances have become the rule rather than an exception. A stressor can be either an abiotic as well as a biotic factor (Cottingham 1999; Vinebrooke et al. 2004) that exceeds its range of normal variation and affects individual physiology, population performance or community balance in a significant way. Similarly, most other definitions of ecological stress (e.g. Barrett et al. 1976; Auerbach 1981; Underwood 1989; Hughes \& Connell 1999) include the effects at individual and demographic (population or functional group) level. At the individual level, stress is considered as a sub-lethal effect on the physiology of an organism, e.g., a decline in feeding, growth, or fecundity, or a biochemical change. At the community or ecosystem level, stress denotes an acute or chronic disturbance that causes a decline in the number of organisms affecting biotic interactions and integrity (e.g, Hyland et al. 2003; Pilière et al. 2014).

Ecosystems as dynamic and self-organizing systems are continuously adapting to a multitude of disturbances (Connell 1978). Rapid increase in anthropogenic pressures has modified the types, frequency and magnitude of disturbances. Some species cannot keep up with these changed disturbance regimes, while others take advantage of the freed-up or new resources (Halpern et al. 2008). At any organisational level, multiple stress situations include biological interactions (e.g. food chain interactions, resource competition), human pressures (which typically alter more than one environmental factor), and impacts of climate change (Ormerod et al. 2010).

A number of theoretical concepts in the field of multiple stressor research underpin on-going research activities on multi-stressor effects. The landscape filter concept (Tonn et al. 1990) explains the structure of river communities as a result of a set of environmental constraints filtering species that can be found at a place. The species co-tolerance model (Vinebrooke et al. 2004) hypothesizes that positive correlation of tolerance of species to multiple stressors increases ecosystem resistance, while negatively correlating tolerance results in additive or synergistic impacts, compared to situations where tolerances of each species are randomly distributed. The related stress-gradient hypothesis highlights a global shift towards positive species interactions with increasing environmental stress. So far, the latter has been tested mostly on vascular plants (He et al. 2013). The 'control species' concept (Downes 2010) advocates measuring the reaction of a group of 'treatment species', which are predicted to respond to a specific gradient against that of 'control species' not sensitive to the stressor of interest because of specific features of their biology or ecology. Simulating in this way the experimental conditions in field situations has a potential to improve our capacity to draw conclusions about causality.

The common analytical approach in multi-stress studies has been to disentangle the effects of confounding factors one-by-one (e.g. Vonesh et al. 2009; Battarbee et al. 2012) and specify the cause-effect chains underlying these relationships. This requires careful hypothesis-driven research, often combining field studies with experiments and modelling, to discover the intimate linkages between species and/or functional groups and their environment (Downes 2010; 
Ormerod et al. 2010). By now, this massive and continuing effort has revealed: (i) a huge variation in impact-response relationships across different aquatic environments (Verdonschot et al. 2013), seasons (Lytle \& Poff 2004), climatic regions (Wasson et al. 2010), and biotic communities (Johnson et al. 2006); (ii) a domination of non-linear and often lagged responses in biotic reactions to stressors (Dodds et al. 2010); (iii) dependence of a particular stress effect with perturbation history (Hughes \& Connell 1999); and (iv) stressor's interactions amplifying or dampening each-other's effects (Folt et al. 1999; Micheli et al. 2013).

Against this background it seems rather obvious that multiple stressors pose specific challenges for aquatic ecosystem management (Hering et al. 2015). Practical knowledge is urgently required not only on the additive effects of multiple stressors (implying that management addressing the largest stressor will have the greatest benefit), but also on their interacting effects, because future rates of ecosystem decline predicted on the basis of individual stressor effects will be underestimated (Brown et al. 2013). However, current management practice generally does not integrate scientific evidence on multi-stressor effects. The main aim of this review is thus to assess the quantity and quality of the scientific evidence base on multiple stress effects in aquatic ecosystems including rivers, lakes, transitional and coastal (TraC) waters, and groundwaters. In particular, we address the following questions:

- Which stressor combinations are commonly documented in scientific literature?

- How strong are these effects across different aquatic environments and biological response variables?

- How reliable is this evidence with regard to the underlying data quality?

- How common are non-additive, i.e. synergistic and antagonistic effects?

The collated evidence is intended to provide a fundamental contribution to the design of a diagnostic tool supporting multi-stressor management in aquatic systems under the European Water Framework Directive (WFD). We expected to find knowledge gaps, i.e. multi-stress situations for which conceptual knowledge exists but the effects are not quantified. We also hypothesised that the same drivers are responsible for the dominating stressor combinations in all aquatic environments, but that the responses differ between those due to diverging sensitivity. Finally, we questioned whether the different research traditions in rivers, lakes, and TraC waters are reflected in the methodological approaches used in multi-stressor studies. 


\section{Material and methods}

\subsection{Literature selection}

For the literature survey, we used the ISI Web of Science citation databases (see Supplementary material for the combination of search terms used in the queries). Although zooplankton is not a mandatory biological group for the WFD, it was included as a search string for lakes because the central position of zooplankton in lake food webs renders a high indicative value to it in multistress situations (Altshuler et al. 2011; Jeppesen et al. 2011a). Since the aim was to find papers in which the multiple stress effects were quantitatively described, we screened the retrieved papers for that. The search was extended by a 'snowball' approach looking through the references in relevant papers. We excluded ecotoxicological lab experiments with single species as test organisms, or bioassays done only with natural stressors (e.g. Przeslawski et al. 2015).

Due to different research traditions and the prevailing hydrogeological paradigm in groundwater research, different search terms were used in the literature search (see Supplementary material). Biological indicators, irrelevant for groundwaters, were skipped and the papers were screened for water quality and quantity indicators.

Given that the review covered a major part of aquatic ecology and groundwater research, the retrieved set of papers does not pretend to completeness, but is expected to give a relatively comprehensive and representative cross-cut of prevailing stressor combinations, preferred indicators, and ways of quantification of complex stressor-interactions. Additional literature on simple (additive) stressor settings which are often not highlighted as multiple stressor impacts, is certainly available, but the attempt to include it all would have been unfeasible workload-wise.

\subsection{Review table}

Relevant information from the papers was extracted to a spreadsheet to enable a synthesis of the literature (see Review Table.xlsx in Supplementary materials). According to the concept, each effect of combined stressors on a response variable (a 'bivariate association' sensu Ziegler et al. 2015) described in a quantitative way forms an 'evidence item' (EI) sensu Webb et al. (2015) that was entered into a separate row of the table. Papers containing more than one EI thus covered several rows of the table (Table 1). The table includes also some conceptual and review papers which not necessarily quantify multi-stressor effects but which we considered important as background information. Since the behaviour of groundwater systems relies heavily on sitespecific hydro-, geo- and pedological settings, the relationships were mostly of conceptual type and almost no quantifying equations could be found that would be valid anywhere else.

Table 1. Number of papers included in the review and number of multi-stress evidence items described for different aquatic environments.

\begin{tabular}{|l|l|l|l|l|l|}
\hline Counting units & Rivers & Lakes & Transitional & Groundwaters & Total \\
\hline
\end{tabular}




\begin{tabular}{|l|l|l|l|l|l|}
\hline & & & and coastal & & \\
\hline Papers & 75 & 65 & 33 & 46 & 219 \\
\hline Multi-stress evidence items & 214 & 152 & 120 & 46 & 532 \\
\hline
\end{tabular}

We divided the review task among co-authors by the four types of aquatic environments so that for each of them the table was filled in by investigators working with the specific types of waters. In order to further join the tables into one to enable a common analysis, the column structure of the tables for the four types of aquatic environments was kept similar. Each table contained bibliographic data; a narrative description of the EI and its implications for management or ecosystem services; spatial and temporal scale of the study (number of water bodies, geographic location and type, temporal scale of the data); driving forces (the main climatic and anthropogenic drivers; EEA, 1999); stressors and covariates (climatic, hydrological, morphological, thermal/optical, chemical, trophic, toxic, and biological stressors; each sub-divided into more specific direct stressors); response variables including their type (structural or functional, 'snapshot' or time-series) and details on multi-stress-effect models (e.g. regression equation, effect size, ANOVA results); risks involved and ecosystem services impacted.

Three types of entries were used in the different columns:

(i) (Free) text columns were used for the full bibliographic reference and the type of paper, for describing the multi-stress-effect models (the 'Narrative statement'), management implications, study design, statistics used, comments, and for explaining the category of 'other' under water body type location, and the driving forces of stress.

(ii) Numeric entries were used for publication year, the number of water bodies included in the study, temporal scale of the source data (in years), and the strength of the described relationship (coefficient of determination: $\mathrm{R}^{2}$ ).

(iii) " 1 " was used as a tick mark denoting 'Yes' for selecting one (or more) of the multiplechoice columns for the categories: aquatic environments, study scale, driving forces, stressors, indicators, risks involved and ecosystem services impacted.

Cells were left empty, if the choices were 'No', 'non-applicable' or 'not indicated'.

Effects on ecosystem services were assessed based on our expert judgement. For surface waters we used the MAES/CICES (Maes et al. 2014) conceptual framework, in which only ecosystem services (ES) provided by biota are considered. Hydropower and navigation were thus not considered as ecosystem services. For groundwaters, two additional ES (strategic reserves and groundwater dependent ecosystems) were used.

\subsection{Meta-analysis}

The data synthesis was carried out at two levels: (i) at the paper level we summarised the publication year, geographic distribution, time frame of data collection, number of water bodies 
analysed, and the broad types of response variables used (termed 'metrics' in the following, see below); (ii) at the EI level the multi-stress-effect models were analysed in more detail. To test the hypotheses that the same drivers are responsible for the dominating stressor combinations in all water categories, but the responses differ between categories, we carried out a descriptive comparison across different aquatic environments based on the numeric values and number of entries (indicated by tick-marks) in different columns. As the number of papers and EIs differed between the aquatic environments, the comparison was mostly done using relative proportions. A Z-test to compare proportions in two populations (to test whether they differ significantly) was done using the online calculator at http://www.socscistatistics.com/. Correlation analysis and Mann-Whitney test were carried out with STATISTICA 12 (StatSoft, Inc. 2014).

To check our intuition that the different research traditions in rivers, lakes, and TraC waters are, first of all, reflected in the selection of response metrics, we analysed the broad types of metrics responding to multi-stress effects used in the four aquatic environments. For this purpose, we distinguished the following three types of metrics:

(i) Metrics of simple structure (SS) including, for instance, stratification structure, water level, temperature, matter concentrations in the water, taxon abundances and biomasses, fish size and age structure, species richness, diversity, evenness, macrophyte zonation.

(ii) Metrics of functional structure (FS). For surface waters they include structural metrics with functional attributes (e.g. biological features related to tolerance, trophic position, reproduction, habitat and migration). Metrics of this group are sometimes termed 'functional metrics' (e.g. Hering et al. 2004, Pont et al. 2006). For groundwaters, metrics of functional structure included, for instance, aquifer vulnerability factors such as soil properties, hydraulic conductivity, pressure or pathway parameters, and coastal topography.

(iii) Functional or process metrics (P; sensu Palmer \& Febria 2012), i.e. metrics characterising matter fluxes, or rates and equilibria of processes such as nutrient uptake, photosynthesis, growth rate, respiration rate etc. For groundwaters, they comprise water budget components, salt water intrusion or refreshing rate, base flow etc. At least two point measurements are needed for most process metrics to capture the time dimension. Exceptions of this rule are, for instance, the length of fish year classes including a hidden time dimension, or the annual maximum biomass of macrophytes reflecting their productivity.

For each metric type we checked whether a 'snapshot' measurement or a time series was used. Metrics with dynamics measured as time series were marked with 'd' (correspondingly, SSd, FSd and Pd). Multimetric indices composed of different types of metrics were analysed based on the single component metrics used. SS and FS were summed up as 'static metrics' while SSd, $\mathrm{FSd}, \mathrm{P}$ and Pd as 'dynamic metrics'. 


\section{Results}

The selected 219 papers covered a period of 29 years, ranging from 1986 to 2014 with steadily increasing numbers of publications per year towards the end of the period (Supplementary Material [SM] Fig. S1). The number of papers by aquatic environments ranged from 33 for TraC waters to 75 for rivers (SM Table S1). For all aquatic environments, the largest number of papers was from Europe (53\%), followed by North America (21\%) and multi-continental studies (13\%). Highest median numbers of water bodies per study were analysed for rivers, followed by TraC waters, lakes and groundwaters (SM Fig. S2). Case studies of single water bodies contributed $5 \%$ of the river evidence base, about $30 \%$ of lake and TraC waters' evidence bases and nearly $50 \%$ of the groundwater evidence base. The median time window for data collection was 0.1 years for rivers and ranged from 7.5 to 9 years for other aquatic environments (Fig. 1).

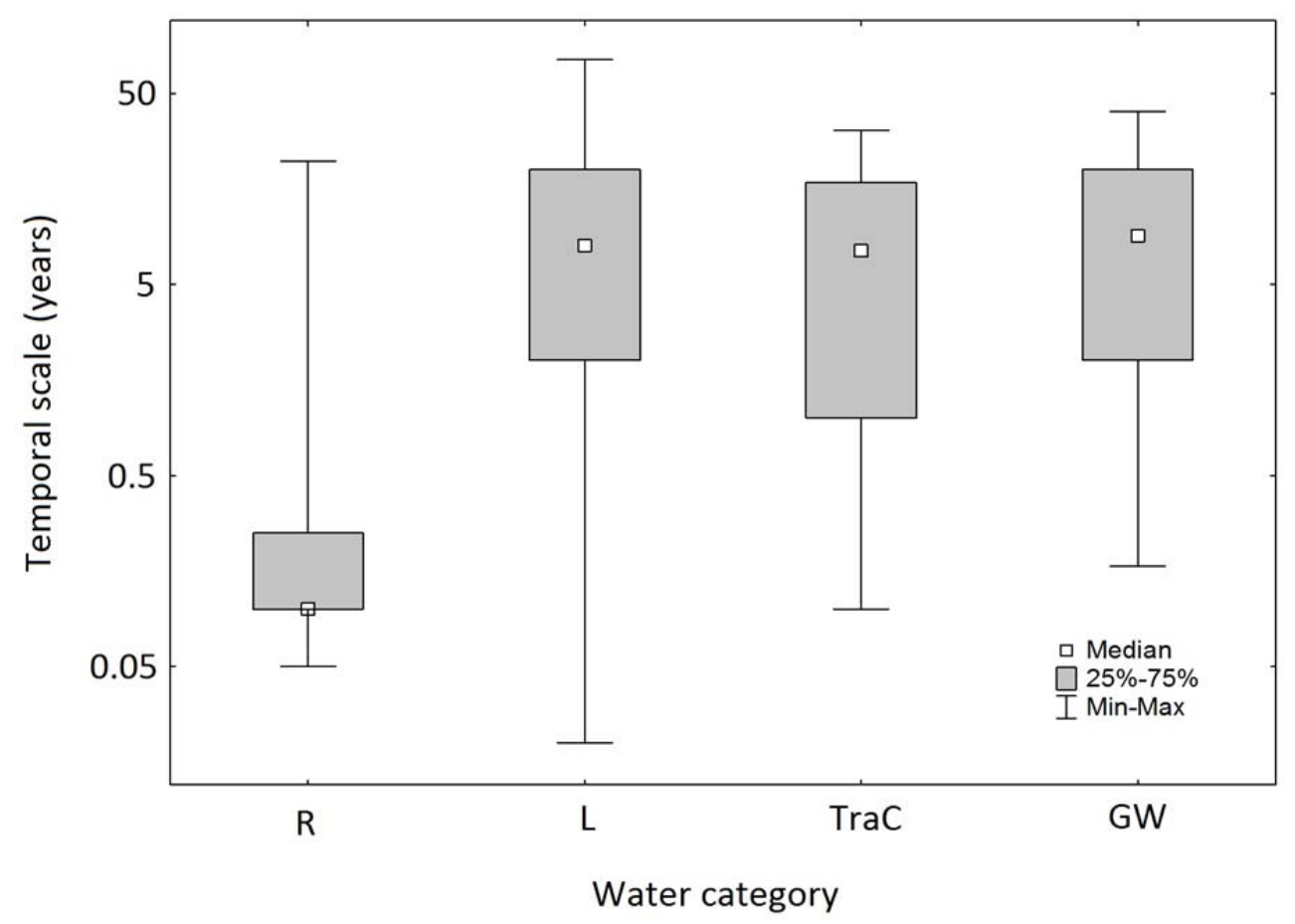

Fig. 1. Time scale of data collection used in studies of different aquatic environments. $R-$ rivers; $L-$ lakes; TraC - transitional and coastal waters; GW - groundwaters.

Nutrient stressors represented the predominant stress group, being studied in more than $70 \%$ of multi-stress situations described for rivers, lakes and TraC waters (Table 2). Still, hydrological stressors dominated in rivers (74\%) and were overwhelming in groundwaters $(83 \%)$. For TraC waters, toxic stressors were represented in $47 \%$ of cases, followed by hydrological stressors (45\%). The bulk of most frequent stress situations in all aquatic environments was formed by nutrient and hydrological stressors in combination with other stressors (Table 3). 
article published in Science of the Total Environment, 2015, vol. 540, 43-52

The original publication is available at www.sciencedirect.com

Doi : 10.1016/j.scitotenv.2015.06.045

Table 2. Stressor groups by aquatic environments (number of Evidence Items and \% of total Evidence Items).

TraC - transitional and coastal waters; GW - groundwaters; $n$ - number; $\%$ - percentage.

\begin{tabular}{lcccccccc}
\hline & \multicolumn{2}{c}{ Rivers } & \multicolumn{2}{c}{ Lakes } & \multicolumn{2}{c}{ TraC } & \multicolumn{2}{c}{ GW } \\
\cline { 2 - 9 } & $\mathbf{n}$ & $\%$ & $\mathbf{n}$ & $\%$ & $\mathbf{n}$ & $\%$ & $\mathbf{n}$ & $\%$ \\
\hline Nutrient stressors & 152 & 71 & 119 & 78 & 117 & 98 & 20 & 43 \\
Hydrological stressors & 159 & 74 & 61 & 40 & 54 & 45 & 38 & 83 \\
Morphological stressors & 64 & 30 & 21 & 14 & 46 & 38 & 0 & 0 \\
Thermal/optical stressors & 46 & 21 & 47 & 31 & 12 & 10 & 0 & 0 \\
Chemical stressors & 26 & 12 & 21 & 14 & 14 & 12 & 17 & 37 \\
Toxic stressors & 48 & 22 & 18 & 12 & 56 & 47 & 10 & 22 \\
Biological stressors & 21 & 10 & 42 & 28 & 33 & 28 & 0 & 0 \\
Total evidence items & 214 & & 152 & & 120 & & 46 & \\
\hline
\end{tabular}

Table 3. The three most dominant two-stressor combinations $\left(1^{\text {st }}, 2^{\text {nd }}, 3^{\text {rd }}\right)$ for lakes $(L)$, rivers $(R)$, transitional and coastal waters (TraC), and groundwaters (GW).

\begin{tabular}{lcccccc}
\hline & $\begin{array}{c}\text { Hydrological } \\
\text { stressors }\end{array}$ & $\begin{array}{c}\text { Morphological } \\
\text { stressors }\end{array}$ & $\begin{array}{c}\text { Thermal } \\
\text { stressors }\end{array}$ & $\begin{array}{c}\text { Chemical } \\
\text { stressors }\end{array}$ & $\begin{array}{c}\text { Toxic } \\
\text { stressors }\end{array}$ & $\begin{array}{c}\text { Biological } \\
\text { stressors }\end{array}$ \\
\hline Nutrient stressors & $\begin{array}{c}\mathrm{R}\left(1^{\mathrm{st}}\right), \mathrm{L}\left(1^{\mathrm{st}}\right), \\
\operatorname{TraC}\left(2^{\mathrm{nd}}\right)\end{array}$ & $\mathrm{R}\left(2^{\mathrm{nd}}\right), \operatorname{TraC}\left(3^{\mathrm{rd}}\right)$ & $\mathrm{L}\left(2^{\mathrm{nd}}\right)$ & & $\operatorname{TraC}\left(1^{\mathrm{st}}\right)$ & $\mathrm{L}\left(3^{\mathrm{rd}}\right)$ \\
\hline $\begin{array}{l}\text { Hydrological } \\
\text { stressors }\end{array}$ & & & $\begin{array}{c}\mathrm{R}\left(3^{\mathrm{rd}}\right), \\
\mathrm{GW}\left(1^{\mathrm{st}}\right)\end{array}$ & $\mathrm{GW}\left(3^{\mathrm{rd}}\right)$ & & \\
\hline $\begin{array}{l}\text { Morphological } \\
\text { stressors }\end{array}$ & & & & & \\
\hline Thermal stressors & & & $\mathrm{GW}\left(2^{\mathrm{nd}}\right)$ & & \\
\hline
\end{tabular}

Combined hydrological and nutrient stress was evidenced for $53 \%$ of multi-stress situations described in rivers and $27 \%$ of those in lakes (Fig. 2). For TraC waters, this combination was addressed only slightly less frequently ( $43 \%$ of EIs) than the combination of nutrient and toxic stress (45\%). The frequency of occurrence of various two-stressor combinations in rivers correlated significantly with those in lakes $(r=0.57, p<0.05)$ and $\operatorname{TraC}$ waters $(r=0.63, p<0.05)$, whereas the correlation between the stressor occurrence patterns in lakes and TraC waters was not significant. The number of stressor groups acting in concert ranged from one to seven (Fig. 3 ), but two-stressor combinations were addressed most frequently making up $42 \%$ of all EIs described. TraC waters represented a remarkable exception insofar as four-stressor combinations were studied most often (27\% of all TraC EIs; see Fig. 3).

To benchmark the reviewed scientific evidence against the status-quo of European surface waters, we consulted reports from 26 European Member States concerning which pressures are actually acting most frequently at surface water bodies $(n=108,130$; WISE WFD database, EEA 2015). This effort revealed that among the water bodies affected by more than one pressure, 
two-pressure combinations were most commonly reported $(25 \%$ of the total number of water bodies). Although 'stressors' have a meaning slightly different from 'pressures', the latter denoting the direct environmental effects of an anthropogenic activity (IMPRESS 2002), we compared the most dominant two-pressure combinations reported with the two-stressor combinations most frequently addressed in the scientific literature. For rivers and lakes, the combination of diffuse pollution and hydromorphological alteration (41\% of river and $63 \%$ of lake water bodies with two-pressure combinations, respectively) well corresponded with the existing evidence base on the effects of co-acting nutrient and hydrological/morphological stressors for these aquatic environments. For TraC waters, a combination of diffuse and other pressures (including introduction of alien species, commercial fishing, illegal waste deposits) was most frequently reported for European water bodies (46\%). The stressors resulting from these pressures, along with toxic pollution and hydrological alteration, were most commonly addressed within the four-stressor combinations studied in TraC waters.

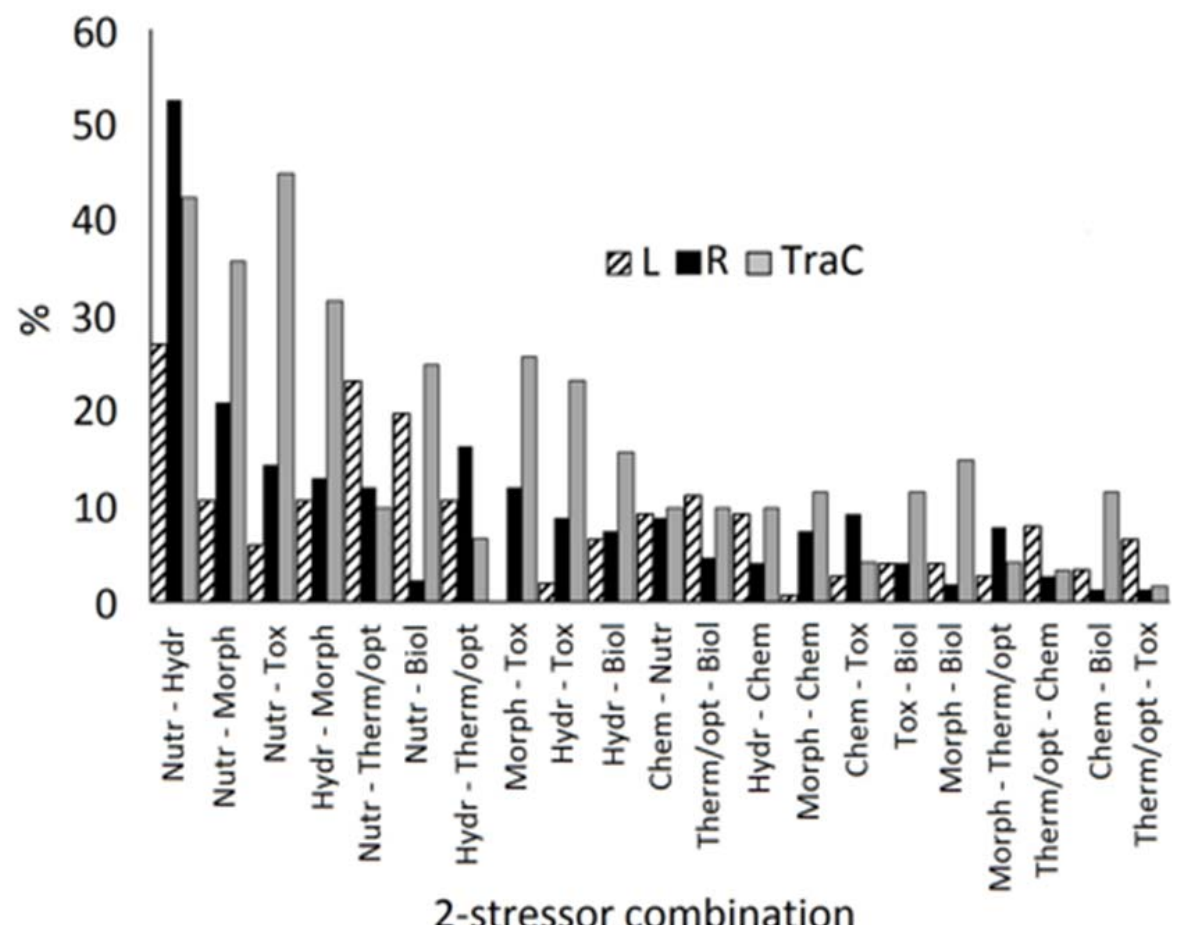

Fig. 2. Frequency counts for the occurrence of two-stressor combinations (\% of Evidence Items) among surface aquatic environments. $R$ - rivers; $L$ - lakes; TraC - transitional and coastal waters. Because combinations by 2 were counted also in cases where there were more simultaneous stressors involved, the percentages add up to a lot more than $100 \%$ for each aquatic environment studied. 


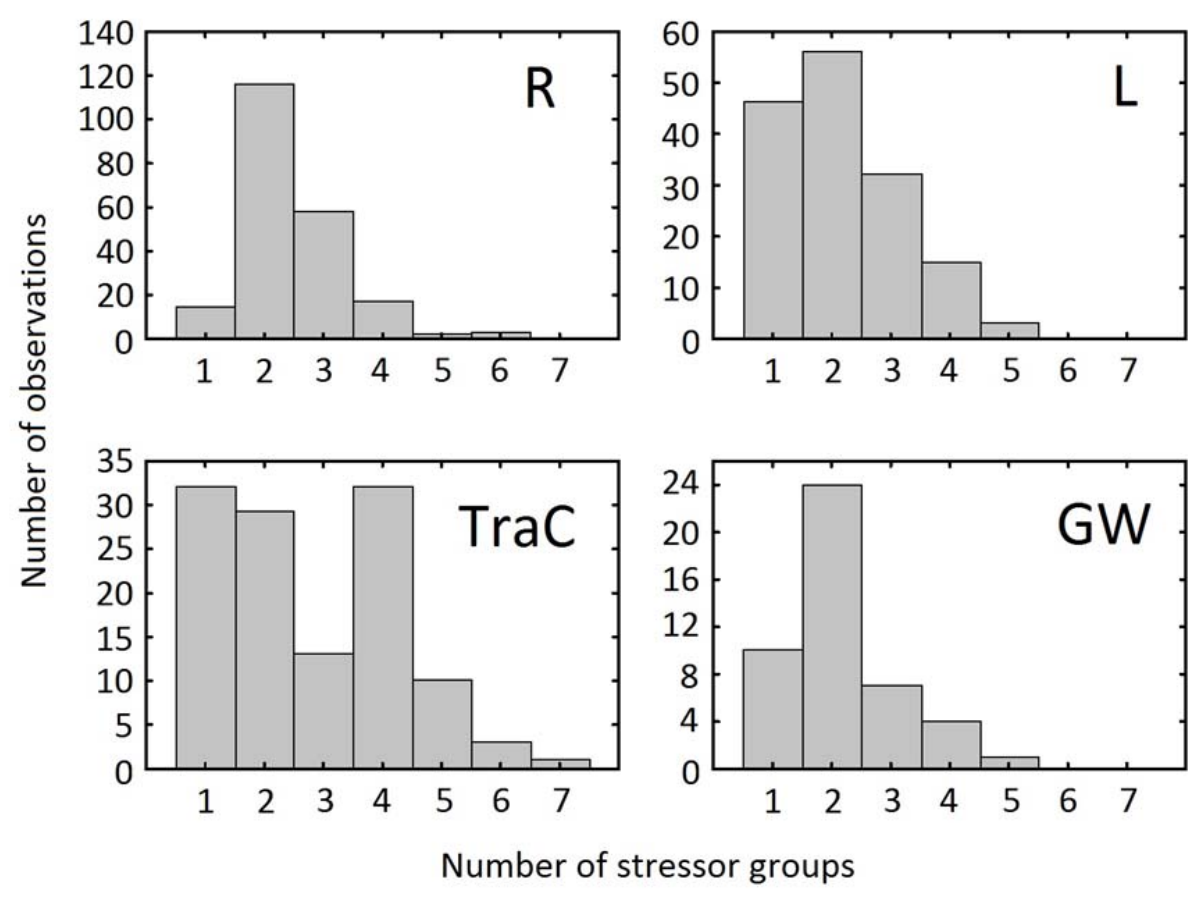

Fig. 3. Number of simultaneously acting stressor groups analysed in the reviewed literature. $R$ - rivers; $L$ - lakes; TraC - transitional and coastal waters; GW - groundwaters. Number of observations given as Evidence Items.

Among the metrics used to indicate the multi-stressor effects, those using benthic invertebrates were most frequently applied in river and TraC studies. Metrics using fish, aquatic macrophytes, zooplankton and physico-chemical parameters were employed almost equally as indicators to study multiple stress effects in lakes (not shown). Phytoplankton metrics occupied only the fifth position in lake studies. Among groundwater studies, most evidence could be found on contamination with nitrates or toxic substances. Metrics describing groundwater quantity or salinity changes also occurred frequently. 


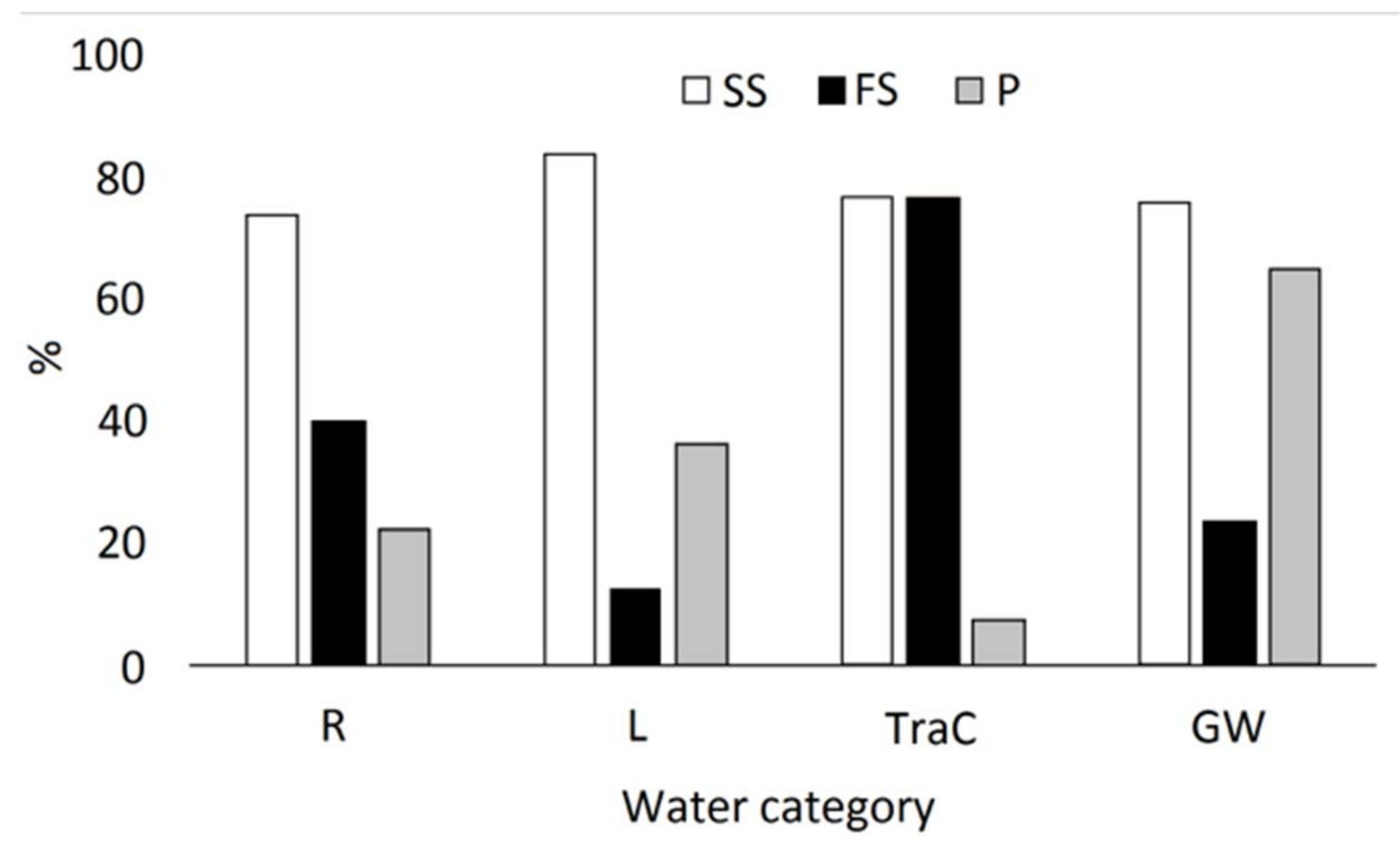

Fig. 4. Percentage of studies in different aquatic environments using multi-stress response metrics describing simple structure (SS), functional structure (FS), and processes ( $P$ ). For each metric type, both 'snapshot' and time series measurements were included. Note that the sum of the percentages is $>100 \%$ because several studies included more than one type of metrics. $R$ - rivers; $L$ - lakes; TraC - transitional and coastal waters; GW-groundwaters.

The analysis of the broad types of metrics used as response variables revealed several peculiarities across aquatic environments: Metrics of simple structure dominated in river, lake, and groundwater studies, showing a percentage between $72 \%$ and $83 \%$; in TraC studies they were equally represented with metrics describing functional structure (Fig. 4). Metrics of functional structure were significantly more often used in TraC studies than in all other aquatic environments $(p<0.01)$, and their frequency was significantly higher for rivers than for lakes $(p<0.01)$. Process metrics were most frequently used in groundwater studies, followed by lake, river, and TraC studies with all differences being significant $(\mathrm{p}<0.01)$.

Static metrics were significantly less often used in groundwater than in surface water studies $(\mathrm{p}<0.05$; SM Fig. S3). Making 'snapshot' measurements was almost similarly popular in all surface aquatic environments, used in more than $70 \%$ of all studies. Dynamic metrics, dominating in the groundwater studies, were equally used with static metrics in the lake studies, and were significantly less frequent in river and TraC studies $(\mathrm{p}<0.01)$. Two-thirds and more of the lake and river studies used only one type of metric, while more than half of $\mathrm{TraC}$ and groundwater studies used two types of metrics simultaneously, often combined into multimetric indices (SM Fig. S4).

The strength $\left(\mathrm{R}^{2}\right)$ values of the described multi-stress-effect models given in the papers varied largely (Fig. 5) with half of them remaining within a range of 0.30-0.59 (median 0.42) for rivers 
and $0.30-0.70$ (median 0.47 ) for lakes. The median was significantly smaller in TraC waters (0.25; Mann-Whitney U-test, $\mathrm{p}<0.01)$ while the $50 \%$ range was broader towards smaller values $(0.14-0.58)$. For groundwaters, the strength of the relationship was not given in most of the studies.

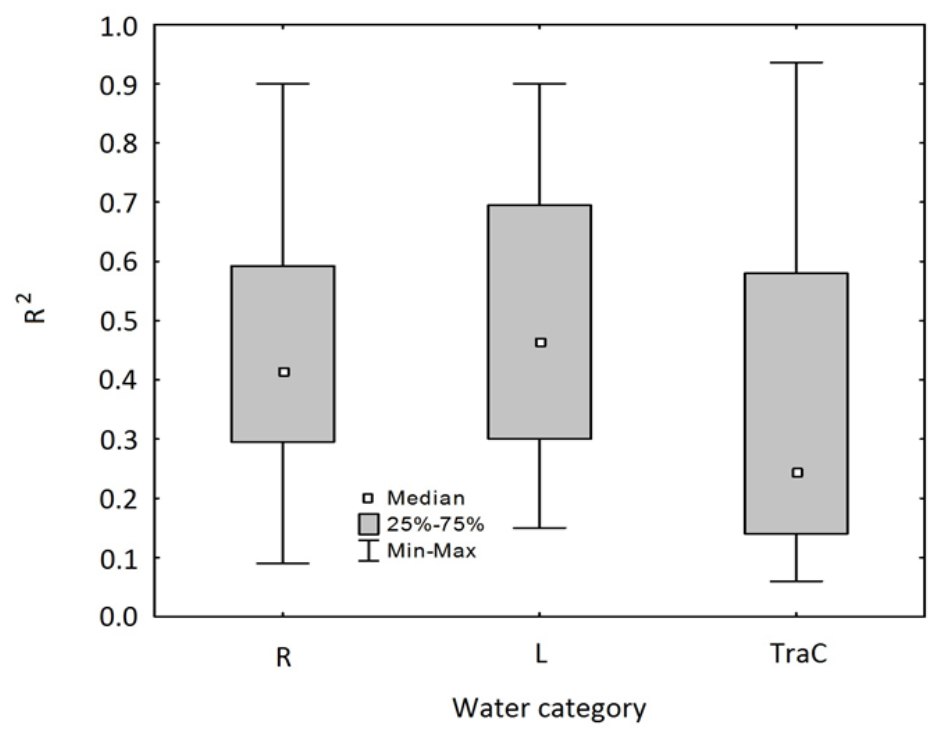

Fig. 5. Strength $\left(R^{2}\right)$ of the described multi-stress-effect models in surface aquatic environments. $R-$ rivers; $L$ - lakes; TraC - transitional and coastal waters.

Across all aquatic environments, the explanatory power of effect models using fish increased when multiple stressors were taken into account in the analysis (Fig. 6). The coefficient of determination resulting from regressing the number of stressor groups against the explanatory power of the reviewed effect models amounted to $\mathrm{R}^{2}=26 \%$. Contrary to this, the explanatory power of models using benthic flora decreased in multiple stress situations, i.e. the more stressor groups taken into account the less explanatory power was achieved $\left(R^{2}=12 \%\right.$; Fig. 6). Phytoplankton and benthic invertebrates showed no significant difference in their explanatory power. The data for zooplankton and multi-metric indices (including metrics from several biological groups) was too limited to see any pattern in their response. 

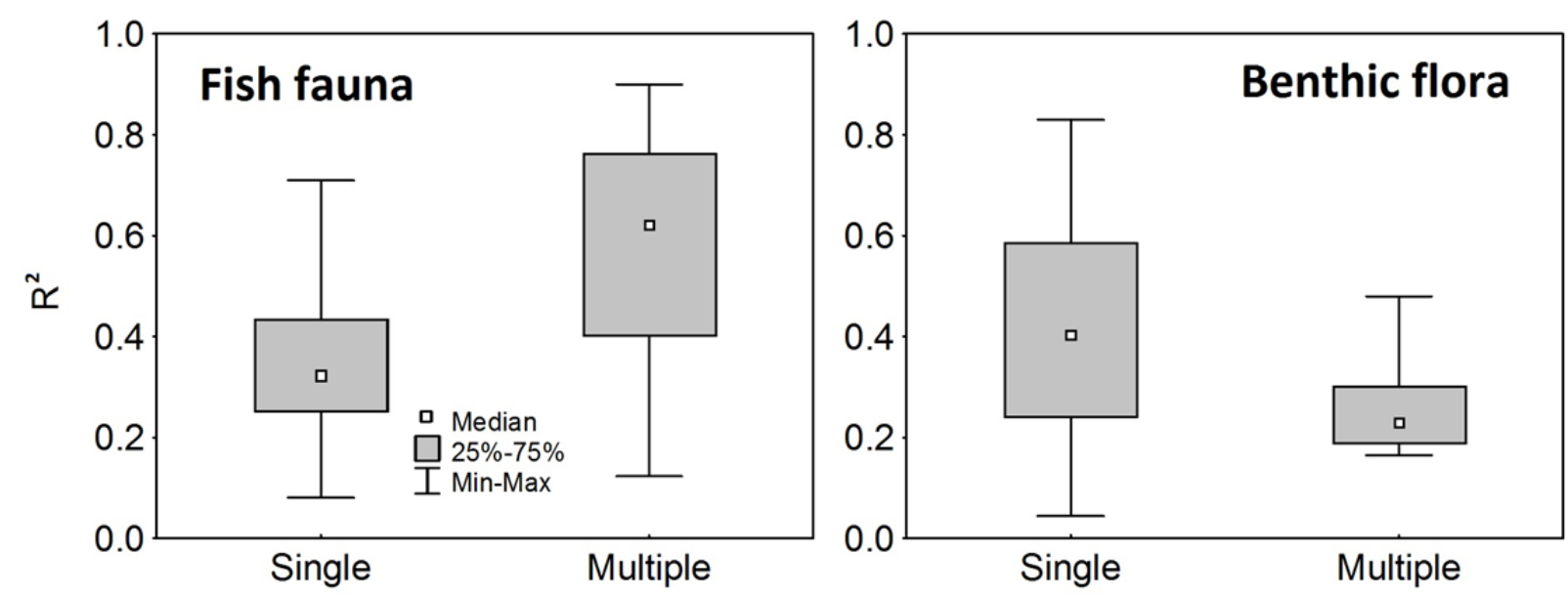

Fig. 6. Significant differences in explanatory power $\left(R^{2} ; p<0.01\right)$ between single and multiple stress-effect models by biological group. Multiple stress models included combinations up to four stressor groups. Data on single pressure cases $(N=56)$ were taken from a review of national assessment methods (Birk et al. 2012). Effect model results for the fish fauna analysis covered evidence from rivers $(n=27)$ and lakes $(n=19)$. Effect model results for the benthic flora analysis covered evidence from rivers $(n=27)$, lakes $(n=12)$ and TraC waters $(n=12)$.

Across all biological groups, the explanatory power of effect models increased when multiple stressors were considered in lakes. The coefficient of determination gained from regression analysis of the number of stressor groups against the model results was $\mathrm{R}^{2}=11 \%$. In TraC waters, the opposite trend was observable: Multiple stressors decreased the effect size, revealing an $\mathrm{R}^{2}$ of $9 \%$ (Fig. 7). The response remained unclear in rivers.
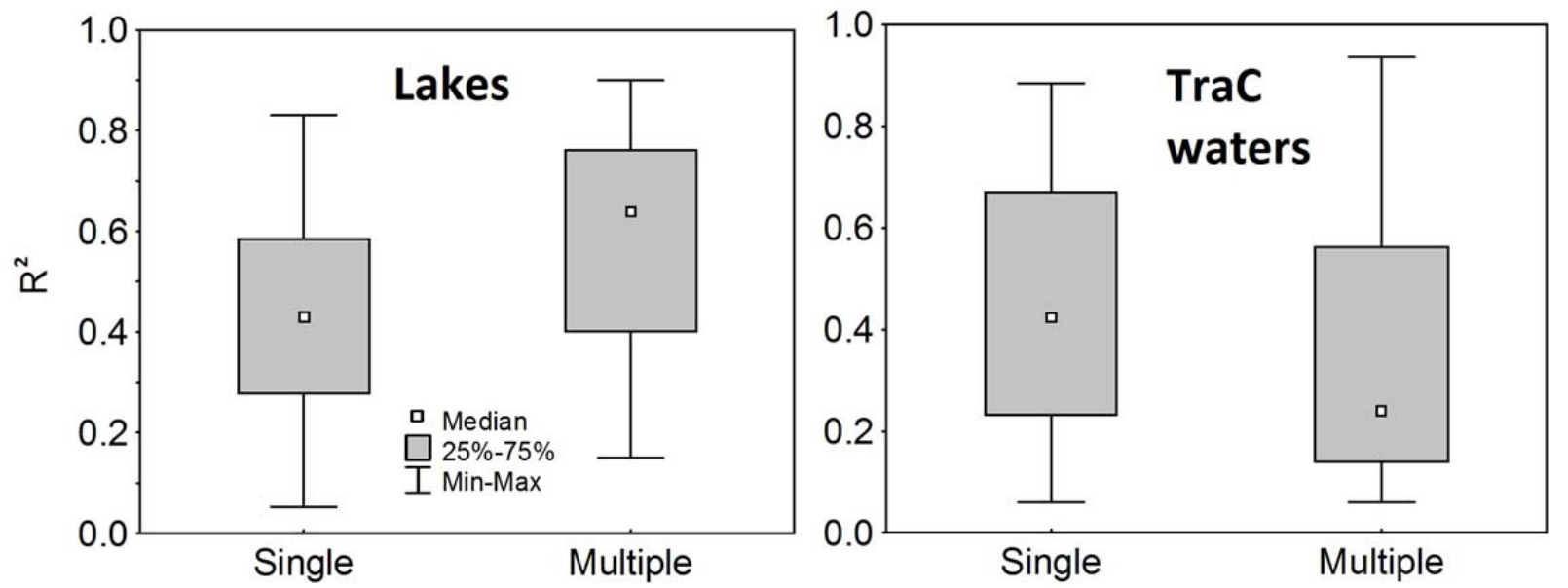

Fig. 7. Significant differences in explanatory power $\left(R^{2} ; p<0.05\right)$ between single and multiple stress-effect models by aquatic environments. Multiple stress models included combinations up to five stressor groups. Data on single pressure cases $(N=104)$ were taken from a review of national assessment methods (Birk et al. 2012). Effect model results for lakes covered evidence from phytoplankton $(n=20)$, benthic flora $(n=12)$, benthic invertebrates $(n=8)$ and fish fauna $(n=27)$. Effect model results for TraC waters covered evidence from phytoplankton $(n=9)$, benthic flora $(n=12)$ and benthic invertebrates $(n=92)$. 
Author-produced version of the article published in Science of the Total Environment, 2015, vol. 540, 43-52

The original publication is available at www.sciencedirect.com

Doi : 10.1016/j.scitotenv.2015.06.045

The type of interaction between stressors (additive, synergistic or antagonistic) was indicated in more than $50 \%$ of cases in river and groundwater studies, but only in $15 \%$ of cases in lake and TraC studies (Fig. 8). All types of interactions between stressors were represented in all aquatic environments. Synergistic interactions dominated in groundwater studies, additive interactions in TraC water studies, whereas no clear dominance of any interaction type was found in lake and river studies.

River studies were clearly biodiversity-oriented, whereas in lake and TraC studies biodiversity and water quality risks were equally addressed. According to our expert judgement, all ten main types of ecosystem services provided by biota (Maes et al. 2014) were addressed in the multistress situations described. For rivers, the 'maintenance of physical, chemical and biological conditions' was considered most affected, while for other aquatic environments the studied impacts showed more equal distribution across different service categories.
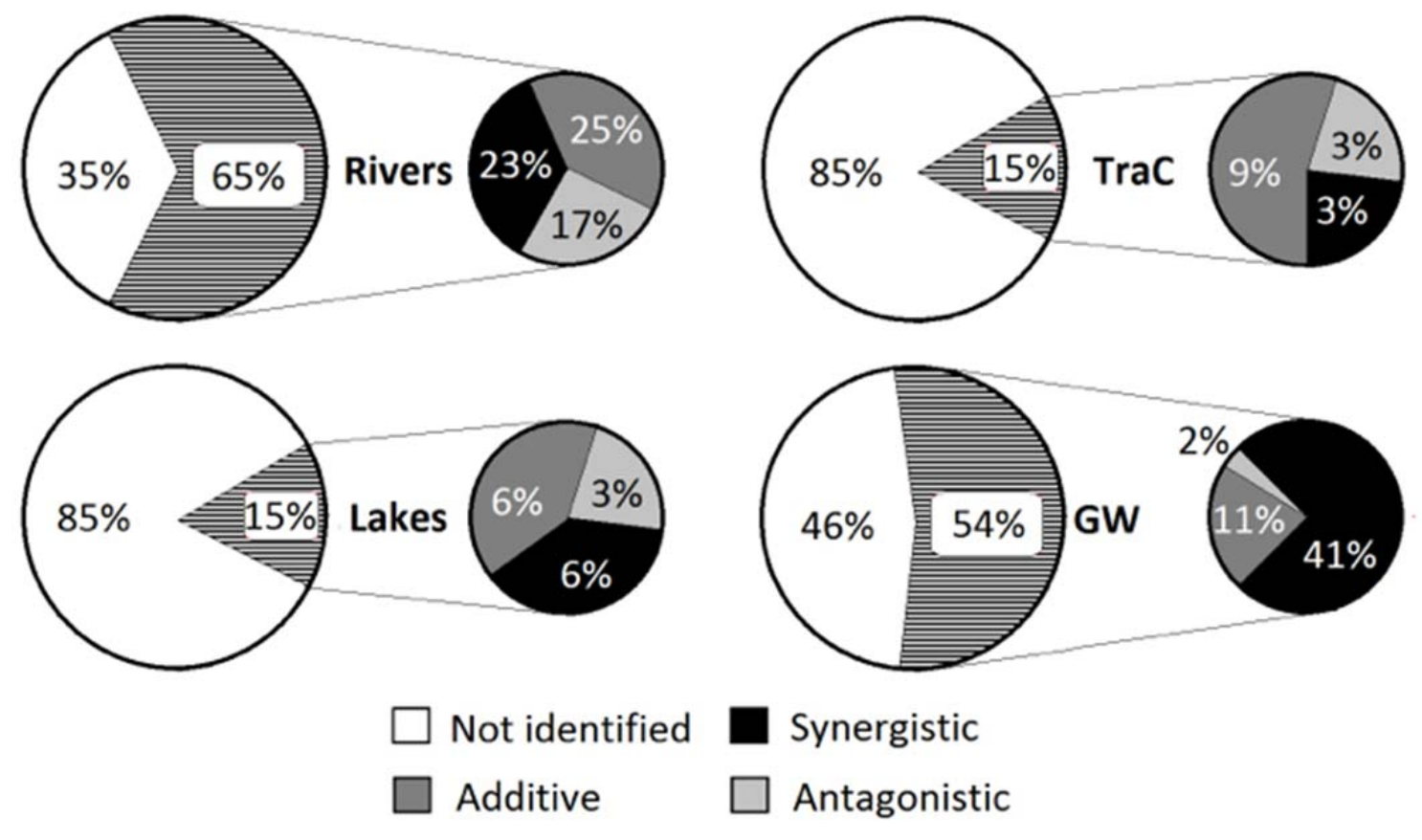

Synergistic

Antagonistic

Fig. 8. Interactions between stressors in multiple stress relationships described for different aquatic environments. TraC - transitional and coastal waters; GW-groundwaters. 


\section{Discussion}

\subsection{The need for quantitative evidence}

The review underlines that despite the importance of multiple stressor issues for both science and management, paradoxically poor elaboration of this field is mirrored by the existing research. Ormerod et al. (2010) and Downes (2010) already pointed out the limited capacity to correctly predict the effects of almost any human activity impacting aquatic ecosystems. This assessment is even more pessimistic if the effects of multiple stressors need to be disentangled.

In our view, the reasons why multi-stress effects have not been adequately assessed so far are manifold: (i) the stressor descriptions are still not fully harmonised impeding large scale analyses; (ii) the collected biological information is not appropriate (insensitive) for analysing the effects of combined stressors; and (iii) the collected data has insufficient temporal or spatial resolution to detect the impacts of relevant stressors. For instance, time series are still lacking for several biological groups in a lot of water bodies, preventing long-term effect analyses. Sampling in lakes where time series exist to a certain extent is often limited to one pelagic sampling point failing to notice warning signals in the more sensitive littoral areas.

Common principles are needed in order to coordinate Europe's efforts to protect and restore the continents' water bodies. Understanding the effect chain in multiple stress situations is evidently important for restoration ecology - an emerging field in aquatic ecology, requiring site-, timeand biological group-specific approaches (Verdonschot et al. 2013). Here, the knowledge of quantifiable responses to multiple stressors can serve as the basis for risk assessment and appropriate management actions. Decision support systems for causal analysis, such as CADDIS (Norton et al. 2009) and Eco Evidence (Webb et al. 2015), use scientific literature to inform evidence-based decision making in environmental management. Both applications rely on literature databases containing information on stressor-response associations reported in the peer-reviewed scientific literature. On this basis, they allow for implementing qualitative causeeffect relationships to support effective water management.

\subsection{Quantity and quality of the multi-stressor evidence base}

Our review revealed that despite the existence of a huge conceptual knowledge base in aquatic ecology, only few studies actually provide quantitative evidence on multi-stress effects. Hence, the quantitative relationships described so far cover just a tiny part of the conceptual schemes commonly reported. While selecting the papers for this review, we were very often unable to find sufficient quantitative evidence in the literature - many of the linkages seem to be accepted as common knowledge, obviating the need for evidence accounting (see also Miller et al. 2013). This finding, in fact, constitutes a valuable outcome by itself, highlighting the need for further research.

We generally see two main issues regarding the establishment of quantitative multi-stressor approaches: Firstly, the large proportion of single water body-based evidence items across lakes, 
TraC waters and groundwaters poses the risk of 'confirming' linkages on the basis of very little, and thus poor evidence - even if the relationships are statistically strong. This problem can be avoided using a formal method for evidence-synthesis, e.g. as employed by the Eco Evidence tool for decision making (Webb et al. 2011). Secondly, it is tempting to add more and more detail to the multi-stress-effect models, finally blurring the picture and 'diluting' the research outcomes. Once you make your model too detailed, there is never enough evidence to conduct a robust synthesis. Identifying a limited number of linkages most relevant for investigation is helpful in this regard. The two to four simultaneous stressor groups addressed by most of the reviewed studies may render an optimal number, depending on the local conditions.

\subsection{Differential expression of nutrient stress along the river-lake-transitional- coastal continuum}

In line with the recent review by Verdonschot et al. (2013), our analysis revealed that all aquatic environments are affected by the same stressors, originating primarily from human population growth, increases in anthropogenic land use and changes in water usage. However, pathways and impacts differ between aquatic environments, depending on the systems' sensitivity. Excess nutrients representing the main physico-chemical stressor were involved in the majority of multi-stress situations in surface waters, but in less than half of those in groundwaters in which, due to strong phosphorus retention, only nitrogen levels remain an issue (Valett et al. 1996). Thus, the impact of nutrients was expressed differently along the groundwater-river-laketransitional-coastal continuum, determined mainly by the different hydro-morphological features of these ecosystems.

Rivers, and partly transitional waters, are characterised by (i) high benthal-to-pelagial habitat ratios resulting in higher relevance of morphological stress affecting the benthic habitats, and (ii) directional flow and low retention times resulting in lower relevance of physico-chemical stress, and higher relevance of hydrological stress, especially when affecting the retention time. This implies that rivers may transport large inorganic nutrient loads without manifest signs of impact. Nevertheless, the sensitivity to nutrients increases if flow conditions stagnate, e.g. during drought or manipulated flow (Lake 2003). Dynamic flow, temperature and salinity gradients in transitional waters create strong natural stress in the freshwater-saltwater transition zone resulting in lower species diversity when compared to higher salinity areas (e.g. Remane 1934). Morphometry and topography controlling flow regime and water exchange also determine the sensitivity of these systems to other stressors. Nitrogen, for instance, which may have passed the freshwater systems without visible impact, may become the determining nutrient causing eutrophication in TraC waters.

Lakes and TraC waters are characterised by (i) low benthal-to-pelagial ratios resulting in lower relevance of morphological stress, acting only locally at shorelines or when water levels are strongly affected, and (ii) high retention times implying higher relevance of physico-chemical stress, and lower relevance of hydrological stress. In lakes the impact of inorganic nutrients, especially phosphorus, accrues when the flow slows down at the mouth of discharging rivers. 
The effect is nonlinearly depending on retention time (Elliott et al. 2009). These authors also showed the importance of the phosphorus source (point vs. non-point) in determining the influence of retention time on phytoplankton. The sensitivity of lakes to nutrient loading and their ability to retain nutrients is determined by their morphometry influencing the hydraulic retention time (Brett \& Benjamin 2008). In TraC waters the local effect of nutrients entering from rivers depends strongly on the exposure and can be suppressed by the dilution effect of advection currents (Gatti et al. 2006).

\subsection{Strength of relationships}

From a purely mathematical viewpoint, the explanatory power of a regression should increase with an increasing number of factors taken into account. This at least holds for systems of constant complexity. However, the papers analysed in our review addressed a large variety of conditions, ranging from rather simple systems dominated by a single stressor, to highly complex systems with up to seven stressor groups acting in concert. Across all biological groups analysed, higher explanatory power of the stress-effect models were discernable only for lakes under multi-stressor compared to single stressor conditions, but not for rivers, coastal and transitional waters. It seems that the more dynamic nature of these ecosystems aggravates significant multi-stressor analysis, adding undesired noise that blurs any meaningful signal. Lake ecosystems as avatars of limnological research obviously represent favourable objects for multi-stressor studies.

The response of the various biological groups to multiple stressors was very ambiguous. Across all aquatic environments, only the explanatory power of fish increased with the number of stressor groups taken into account. This biological group features highly mobile consumers at different levels of the aquatic food-chain, inhabiting both benthic and pelagic habitats. This high niche diversity makes fishes very susceptible to multi-stressor effects. Furthermore, the traitbased approaches largely applied for this group, i.e. functional attributes characterising complex habitat conditions, seems to make it especially useful as holistic indicators in multiple stress situations (Schinegger et al. 2013). The response of benthic flora, including algae and higher plants attached to the bottom sediments, revealed significantly lower explanatory power when multiple stressors were included in the analysis. This organism group is specifically sensitive to nutrient stress and additionally indicative of hydrological stress, including water level changes. In more complex situations the responses to these primary stressors can be diversified resulting in decreasing explanatory power.

\subsection{Different paradigms in aquatic ecosystems' research}

Our meta-analysis revealed a striking difference in the temporal resolution of data collected in rivers compared to other aquatic environments: the bulk of river data is collected using single surveys. An obvious reason for that is the ambiguity of the water body concept for rivers (at least, compared to lakes), described as a continuum or sequence of individual sections of the running water (Vannote et al. 1980). Due to rotation of river stations in many monitoring 
schemes, or due to different lengths of river sections studied, fewer time-series for the same sites are built up. To compensate for the missing time dimension, a large variety of functional attributes of taxa have been developed addressing feeding type, reproduction biology, preferences for biocoenotical region, habitat, and flow velocity (e.g. Hering et al. 2004). Metrics of functional structure were used in $40 \%$ of the river studies analysed reflecting the long tradition, compared to only $8 \%$ in lake studies (see also Birk et al. [2012] for a review of metrics used in ecological status assessment).

The bulk of lake data in the reviewed papers represented time-series of different length up to 85 years (Jeppesen et al. 2012). Leading theories in lake research, e.g. the trophic cascades concept (Carpenter et al. 1985), the alternative stable states concept (Scheffer et al. 1993), the phosphorus limitation paradigm (Vollenweider 1968; reviewed by Sterner 2008) or the microbial loop theory (adopted from marine research; Azam et al. 1983), all concentrate on the dynamics of fundamental processes. Owing to the available long time-series on lakes extendable to thousands of years by palaeo-studies of sediments, lakes have recently been recognised as sentinels and integrators for the climate change effects on watersheds, airsheds and landscapes (Schindler 2009). Although process parameters reflecting nutrient dynamics, community metabolism, or food web processes were significantly more often described in lakes compared to rivers and marine waters, still the majority of 'dynamic' metrics was constituted by timeseries of simple structure metrics, while functional structure metrics were least developed for lakes.

The vast majority of TraC studies reviewed pertain to the last decade (2005-2014) and mostly address the new methods developed to satisfy the WFD requirements. By nature, TraC waters range by exposure or connectivity to the world's ocean, from topographically open systems to semi-enclosed and enclosed systems (Lindgren \& Håkanson 2007), largely defining the water retention time. Due to this large topographic variability, the conditions in $\mathrm{TraC}$ waters range from highly dynamic - comparable to rivers, to highly stable - comparable to lakes. Considerable salinity gradients in transitional waters add to the variability of habitat conditions. Assessment methods addressing multiple stressors in TraC waters are in most cases based on indices composed of a number of metrics of simple and functional structure.

We could not find studies quantitatively describing multiple stressor effects in groundwater ecosystems although qualitative studies exist and have been reviewed by Stendera et al. (2012). The reviewed groundwater studies addressed the abiotic side of groundwater research and were mostly based on physical models that explain the broadest use of process metrics among aquatic environments. Functional metrics were represented by soil properties such as pressure and pathway parameters. 


\section{Conclusions}

The extremely broad problem setting of our review was aiming at describing a status quo in the quantitative multi-stress research across surface water and groundwater environments and finding communalities and differences between stressor combinations and response patterns in these systems. The results corroborated our hypothesis about the similarity of dominating stressors affecting the various aquatic environments and being represented by broad categories of pollution (mostly by excess nutrients but also toxins) and hydromorphological modification of the water bodies. The mostly source based classifications of stressors used in water management cause a seemingly unlimited (i.e. unmanageable) number of potential stressor combinations which makes reaching of robust and effective solutions practically impossible. For understanding the possible impacts, the central questions are how the "stressor field" is translated into a limited number of biologically sensible signals in different aquatic environments at species or community levels which we interrogate as indicators of ecological status. Answering of this question has been hampered, on one hand, by the aspiration considering as much simultaneous stressors as possible that, if no weighting of the stressors is done, blurs the general picture. On the other hand, there is a risk of 'confirming' linkages on the basis of very little, and thus poor evidence - even if the relationships in individual studies are statistically strong, and thus extending them to systems where they may be not valid.

\section{Acknowledgements}

This paper is a result of the project MARS (Managing Aquatic ecosystems and water Resources under multiple Stress) funded by the European Union under the 7th Framework Programme, Theme ENV.2013.6.2-1 (Water resources management under complex, multi-stressor conditions). Grant agreement no: 603378, http://mars-project.eu. Preparation of the paper was partly co-financed by the target-financed project IUT 21-2 of Estonian Ministry of Education and Research.

\section{References}

Altshuler, I., B. Demiri, S. Xu, A. Constantin, N.D. Yan, M.E. Cristescu, 2011. An integrated multidisciplinary approach for studying multiple stressors in freshwater ecosystems: Daphnia as a model organism. Integrative and Comparative Biology 51: 623-633.

Argillier, C., S. Caussé, M. Gevrey, S. Pédron, J. De Bortoli, S. Brucet, M. Emmrich, E. Jeppesen, T. Lauridsen, T. Mehner, M. Olin, M. Rask, P. Volta, I.J. Winfield, F. Kelly, T. Krause, A. Palm, K. Holmgren, 2013. Development of a fish-based index to assess the eutrophication status of European lakes. Hydrobiologia 704: 193-211.

Auerbach, S.I., 1981. Ecosystem response to stress: a review of concepts and approaches. In: Barrett, G.W. and R. Rosenberg (eds.), Stress effects on natural ecosystems. John Wiley and Sons Ltd, pp. $29-41$. 
Azam, F., T. Fenchel, J.G. Field, J.S. Gray, L.A. Meyer-Reil, F. Thingstad, 1983. The ecological role of water-column microbes in the sea. Marine Ecology Progress Series 10: 257-263.

Barrett, G.W., G.M. Van Dyne, E.P. Odum, 1976. Stress ecology. BioScience 26: 192-194.

Battarbee, R.W., N.J. Anderson, H. Bennion, G.L. Simpson, 2012. Combining limnological and palaeolimnological data to disentangle the effects of nutrient pollution and climate change on lake ecosystems: problems and potential. Freshwater Biology 57: 2091-2106.

Birk, S., W. Bonne, Á. Borja, S. Brucet, A. Courrat, S. Poikane, A. Solimini, W. van de Bund, N. Zampoukas, D. Hering, 2012. Three hundred ways to assess Europe's surface waters: An almost complete overview of biological methods to implement the Water Framework Directive. Ecological Indicators 18: 31-41.

Brett, M.T., M.M. Benjamin, 2008. A review and reassessment of lake phosphorus retention and the nutrient loading concept. Freshwater Biology 53: 194-211.

Brown, C.J., M.I. Saunders, H.P. Possingham, A.J. Richardson, 2013. Managing for Interactions between Local and Global Stressors of Ecosystems. PLoS ONE 8: e65765.

Carpenter, S.R., J.F. Kitchell, J.R. Hodgson, 1985. Cascading Trophic Interactions and Lake Productivity. BioScience 35: 634-639.

Connell, J.H. 1978. Diversity in tropical rain forests and coral reefs. Science 199: 1302-1310.

Cottingham, K.L. 1999. Nutrients and zooplankton as multiple stressors of phytoplankton communities: Evidence from size structure. Limnology and Oceanography 44: 810-827.

Dodds, W.K., W.H. Clements, K. Gido, R.H. Hilderbrand, R.S. King. 2010. Thresholds, breakpoints, and nonlinearity in aquatic ecosystems as related to management. Journal of the North American Benthological Society 29: 988-997.

Downes B.J., 2010. Back to the future: little-used tools and principles of scientific inference can help disentangle effects of multiple stressors on freshwater ecosystems. Freshwater Biology 55(Suppl 1): $60-79$.

EEA [European Environment Agency], 1999. Environmental Indicators: Typology and overview. European Environment Agency, Copenhagen.

EEA [European Environment Agency], 2015. WISE WFD Database. http://www.eea.europa.eu/data-andmaps/data/wise_wfd - published 12 Nov 2012.

Elliott, J.A., I.D. Jones \& T. Page, 2009. The importance of nutrient source in determining the influence of retention time on phytoplankton: an explorative modelling study of a naturally well-flushed lake. Hydrobiologi a 627: 129-142. DOI: 10.1007/s10750-009-9720-1

Folt C.L., C.Y. Chen, M.V. Moore, 1999. Synergism and antagonism among multiple stressors. Limnology and Oceanography 44: 864-877.

Gatti, J., A. Petrenko, J.-L. Devenon, Y. Leredde, C. Ulses, 2006. The Rhone river dilution zone present in the northeastern shelf of the Gulf of Lion in December 2003. Continental Shelf Research 26: 1794-1805.

Halpern, B.S., S. Walbridge, K.A. Selkoe, C.V. Kappel, F. Micheli, C. D'Agrosa, J.F. Bruno, K.S. Casey, C. Ebert, H.E. Fox, R. Fujita, D. Heinemann, H.S. Lenihan, E.M.P. Madin, M.T. Perry, E.R. Selig, M. Spalding, R. Steneck, R. Watson, 2008. A Global Map of Human Impact on Marine Ecosystems. Science 319: 948-952.

He, Q., M.D. Bertness, A.H. Altieri, 2013. Global shifts towards positive species interactions with increasing environmental stress. Ecology Letters 16: 695-706.

Hering, D., C. Meier, C. Rawer-Jost, C.K. Feld, R. Biss, A. Zenker, A. Sundermann, S. Lohse, J. Böhmer, 2004. Assessing streams in Germany with benthic invertebrates: selection of candidate metrics. Limnologica 34: 398-415.

Hering, D., L. Carvalho, C. Argillier, M. Beklioglu, Á. Borja, A.C. Cardoso, H. Duel, T. Ferreira, L. Globevnik, J. Hanganu, S. Hellsten, E. Jeppesen, V, Kodeš, A. Lyche Solheim, T. Nõges, S. Ormerod, Y. Panagopoulos, S. Schmutz, M. Venohr, S. Birk, 2015. Managing aquatic ecosystems 
and water resources under multiple stress - An introduction to the MARS project. Science of the Total Environment 503-504: 10-21.

Hughes T., J.H. Connell, 1999. Multiple stressors on coral reefs: a long-term perspective. Limnology and Oceanography 44: 932-940.

Hyland, J.L., W.L. Balthis, V.D. Engle, E.R. Long, J.F. Paul, J.K. Summers, R.F. Van Dolah, 2003. Incidence of stress in benthic communities along the U.S. Atlantic and Gulf of Mexico coasts within different ranges of sediment contamination from chemical mixtures. Environmental Monitoring and Assessment 81: 149-161.

IMPRESS (2002). Guidance for the analysis of pressures and impacts in accordance with the Water Framework Directive. Common Implementation Strategy Working Group 2.1. Office for Official Publications of the European Communities.

Jeppesen, E., P. Nõges, T.A. Davidson, J. Haberman, T. Nõges, K. Blank, T.L. Lauridsen, M. Søndergaard, C. Sayer, R. Laugaste, L.S. Johansson, R. Bjerring, S.L. Amsinck, 2011a. Zooplankton as indicators in lakes: a scientific-based plea for including zooplankton in the ecological quality assessment of lakes according to the European Water Framework Directive (WFD). Hydrobiologia 676: 279-297.

Jeppesen, E., T. Mehner, I.J. Winfield, K. Kangur, J. Sarvala, D. Gerdeaux, M. Rask, H.J. Malmquist, K. Holmgren, P. Volta, S. Romo, R. Eckmann, A. Sandström, S. Blanco, A. Kangur, H. Ragnarsson Stabo, M. Tarvainen, A.-M. Ventelä, M. Søndergaard, T.L. Lauridsen, M. Meerhoff, 2012. Impacts of climate warming on the long-term dynamics of key fish species in 24 European lakes. Hydrobiologia 694: 1-39.

Johnson, R.K., D. Hering, M.T. Furse, R.T. Clarke, 2006. Detection of ecological change using multiple organism groups: metrics and uncertainty. Hydrobiologia 566: 115-137.

Lake, P.S., 2003. Ecological effects of perturbation by drought in flowing waters. Freshwater Biology 48: 1161-1172.

Lindgren, D., L. Håkanson, 2007. Functional classification of coastal areas as a tool in ecosystem modeling and management. Manuscript, Inst. of Earth Sci., Uppsala Univ.

Lytle, D.A., N.L. Poff, 2004. Adaptation to natural flow regimes. Trends in Ecology and Evolution 19: 94-100.

Maes J., Teller A., Erhard M., Murphy P., Paracchini M.L., Barredo J.I., Grizzetti B., Cardoso A.C., Somma F., Petersen J.E., A. Meiner, E.R. Gelabert, N. Zal, P. Kristensen, A. Bastrup-Birk, K. Biala, C. Romao, C. Piroddi, B. Egoh, C. Fiorina, F. Santos, V. Naruševicius, J. Verboven, H. Pereira, J. Bengtsson, G. Kremena, C. Marta-Pedroso, T. Snäll, C. Estreguil, J. San Miguel, L. Braat, A. GrêtRegamey, M. Perez-Soba, P. Degeorges, G. Beaufaron, A., Lillebo, D.A. Malak, C. Liquete, S. Condé, J. Moen, H. Östergård, B. Czúcz, E.G. Drakou, G. Zulian, C. Lavalle, 2014. Mapping and Assessment of Ecosystems and their Services. Indicators for ecosystem assessments under Action 5 of the EU Biodiversity Strategy to 2020. 2nd Report. European Commission. Technical Report - 2014 - 080. Publications Office of the European Union, Luxembourg. ISBN 97892-79-36161-6 doi: 10.2779/75203.

Micheli, F., B.S. Halpern, S. Walbridge, S. Ciriaco, F. Ferretti, S. Fraschetti, R. Lewison, L. Nykjaer, A.A. Rosenberg, 2013. Cumulative Human Impacts on Mediterranean and Black Sea Marine Ecosystems: Assessing Current Pressures and Opportunities. PLoS ONE 8: e79889.

Miller, K.A., J.A. Webb, S.C. de Little, M.J. Stewardson, 2013. Environmental flows can reduce the encroachment of terrestrial vegetation into river channels: a systematic literature review. Environmental Management 52: 1201-1212.

Norton, S.B., S.M. Cormier, G.W. Suter II, K. Schofield, L. Yuan, P. Schaw-Allen, C.R. Ziegler, 2009. CADDIS: The Causal Analysis/Diagnosis Decision Information System. Ch. 17. In: Marcomini, A., G.W. Suter II and A. Critto (eds.), Decision support systems for risk-based management of contaminated sites. Springer Science + Business Media, LLC: $351-374$. 
Ormerod, S.J., M. Dobson, A.G. Hildrew, C.R. Townsend, 2010. Multiple stressors in freshwater ecosystems. Freshwater Biology 55: 1-4.

Palmer, M.A., C.M. Febria, 2012. The Heartbeat of Ecosystems. Science 336: 1393-1394.

Pilière, A., A.M. Schipper, A.M. Breure, L. Posthuma, D. de Zwart, S.D. Dyer, M.A.J. Huijbregts, 2014. Comparing responses of freshwater fish and invertebrate community integrity along multiple environmental gradients. Ecological Indicators 43: 215-226.

Pont, D., B. Hugueny, U. Beier, D. Goffaux, A. Melcher, R. Noble, C. Rogers, N. Roset, S. Schmutz, 2006. Assessing river biotic condition at a continental scale: a European approach using functional metrics and fish assemblages. Journal of Applied Ecology 43: 70-80.

Przeslawski, R., M. Byrne, C. Mellin, 2015. A review and meta-analysis of the effects of multiple abiotic stressors on marine embryos and larvae. Global Change Biology 21: 2122-2140, doi: $10.1111 / \mathrm{gcb} .12833$.

Remane, A., 1934. Die Brackwasserfauna. Verhandlungen Der Deutschen Zoologischen Gesellschaft 36: 34-74.

Scheffer, M., S.H. Hosper, M.L. Meijer, B. Moss, 1993. Alternative equilibria in shallow lakes. Trends in Ecology and Evolution 8: 275-279.

Schindler, D.W., 2009. Lakes as sentinels and integrators for the effects of climate change on watersheds, airsheds, and landscapes. Limnology and Oceanography 54: 2349-2358.

Schinegger, R., C. Trautwein, S. Schmutz, 2013. Pressure-specific and multiple pressure response of fish assemblages in European running waters. Limnologica 43: 348-361.

StatSoft, Inc. (2014). STATISTICA (data analysis software system), version 12. www.statsoft.com.

Stendera, S., R. Adrian, N. Bonada, M. Cañedo-Argüelles, B. Hugueny, K. Januschke, F. Pletterbauer, D. Hering, 2012. Drivers and stressors of freshwater biodiversity patterns across different ecosystems and scales: a review. Hydrobiologia 696: 1-28.

Sterner, R.W., 2008. On the Phosphorus Limitation Paradigm for Lakes. Internat. Rev. Hydrobiol. 93: $433-445$.

Tonn, W.M., J.J. Magnuson, M. Rask, J. Toivonen, 1990. Intercontinental Comparison of Small-Lake Fish Assemblages - the Balance between Local and Regional Processes. American Naturalist 136: 345-375.

Underwood, A.J., 1989. The analysis of stress in natural populations. Biological Journal of the Linnean Society 37: 51-78.

Valett, H.M., J.A. Morrice, C.N. Dahm, M.E. Campana, 1996. Parent lithology, surface-groundwater exchange, and nitrate retention in headwater streams. Limnology \& Oceanography 41: 333-345.

Vannote, R.R., G.W. Minshall, K.W. Cummins, J.R. Sedell, C.E. Cushing, 1980. The river continuum concept. Canadian Journal of Fisheries and Aquatic Sciences 37: 130-137.

Verdonschot, P.F.M., B.M. Spears, C.K. Feld, S. Brucet, H. Keizer-Vlek, A. Borja, M. Elliott, M. Kernan, R.K. Johnson, 2013. A comparative review of recovery processes in rivers, lakes, estuarine and coastal waters. Hydrobiologia 704: 453-474.

Vinebrooke R.D., K.L. Cottingham, J. Norberg, M. Scheffer, S.I. Dodson, et al., 2004. Impacts of multiple stressors on biodiversity and ecosystem functioning: the role of species co-tolerance. Oikos 104: 451-457

Vollenweider, R.A., 1968. Scientific fundamentals of the eutrophication of lakes and flowing waters, with particular reference to nitrogen and phosphorus as factors in eutrophication. DAS/CSI/68.27, Organisation for Economic Cooperation and Development, Paris.

Vonesh, J.R., J.M. Kraus, J.S. Rosenberg, J.M. Chase, 2009. Predator effects on aquatic community assembly: disentangling the roles of habitat selection and post-colonization processes. Oikos 118: $1219-1229$. 
total Environment 2015 vol 540

The original publication is available at www.sciencedirect.com

Doi : 10.1016/j.scitotenv.2015.06.045

Wasson, J.-G., B. Villeneuve, A. Iital, J. Murray-Bligh, M. Dobiasova, S. Bacikova, H. Timm, H. Pella, N. Mengin, A. Chanderis, 2010. Large scale relationships between basin and riparian land cover and ecological status of European rivers: examples with invertebrate indices from France,

Estonia, Slovakia and United Kingdom. Freshwater Biology 55: 1465-1482.

Webb, J.A., S.R. Wealands, P. Lea, S.J. Nichols, S.C. de Little, M.J. Stewardson, R.H. Norris, 2011. Eco Evidence: using the scientific literature to inform evidence-based decision making in environmental management. 19th International Congress on Modelling and Simulation, Perth, Australia, 12-16 December 2011. http://mssanz.org.au/modsim2011.

Webb, J.A., K.A. Miller, S.C. de Little, M.J. Stewardson, S.J. Nichols, S.R. Wealands, 2015. An online database and desktop assessment software to simplify systematic reviews in environmental science. Environmental Modelling \& Software 64: 72-79.

Ziegler, C.R., J.A. Webb, S.B. Norton, A.S. Pullin, A. Melcher, 2015. Digital repository of associations between environmental variables: a new resource to facilitate knowledge synthesis. Environmental Indicators 53: 61-69. 